\title{
The Effect of Prunella on Anti-Inflammatory Activity in RAW264.7 Mouse Macrophage Cells
}

\author{
Meehye Kim ${ }^{1,2}$ \\ ${ }^{1}$ Food Safety Evaluation Department, Korea Food and Drug Administration, Cheongwon-gun, South Korea; ${ }^{2}$ Center for Research on \\ Dietary Botanical Supplements, Iowa State University, Ames, USA. \\ Email:meehkim@korea.kr
}

Received October $21^{\text {st }}, 2011$; revised July $23^{\text {rd }}, 2012$; accepted August $30^{\text {th }}, 2012$

\begin{abstract}
The extracts of Prunella vulgaris L. (Labiatae), a popular Western and Chinese herbal medicine, was shown to have anti-inflammatory properties, which might be due to partially, their rosmarinic acid content. Inhition of prostaglandine $\mathrm{E}_{2}\left(\mathrm{PGE}_{2}\right)$ production in lipopolysaccharide (LPS) stimulated RAW264.7 mouse macrophage cells was assessed with an enzyme immunoassay (EIA) following 8-hour treatments with Prunella vulgaris (P. vulgaris) extracts or fractions. Results showed that $95 \%$ ethanol extracts from $P$. vulgaris significantly inhibited $\mathrm{PGE}_{2}$ production. In further studies, fraction 2 from the $95 \%$ ethanol extract of $P$. vulgaris significantly reduced $\mathrm{PGE}_{2}$ production at $66 \mu \mathrm{g} / \mathrm{mL}$ ( $72 \%$ reduction). Cytotoxicity did not play a role in the noted reduction of $\mathrm{PGE}_{2}$ seen in either the extracts or fractions from $P$. vulgaris. High performance liquid chromatography analysis showed that there was $1.4 \mathrm{mM}$ rosmarinic acid in $95 \%$ ethanol Prunella extract $(201 \mathrm{mg} / \mathrm{mL}$ crude extract). Our results suggest that rosmarinic acid may contribute toward the anti-inflammatory activity of Prunella in a dose-response manner. Prunella might have a potential to be used as a functional food for anti-inflammatory activity.
\end{abstract}

Keywords: Prunella vulgaris; Rosmarinic Acid; Ursolic Acid; Anti-Inflammatory Activity; Cytotoxicity

\section{Introduction}

The medical use of herbal products has increased in the world including the United States and Asian countries. Prunella vulgaris L. (Labiatae), a plant known as "selfhealing" was popular in traditional European medicine during the 17th century as a remedy for alleviating sore throat, reducing fever and accelerating wound healing. Prunella vulgaris (P. vulgaris) has also long been associated with anti-viral and anti-bacterial effects [1-5]. Antioxidant, anti-inflammatory, antiviral, and antibacterial effects of $P$. vulgaris extract have been likewise demonstrated $[2,3,6,7]$. Both $P$. vulgaris and laciniata have been shown to stimulate lymphocyte proliferation [8-10].

The genus Prunella (Lamiaceae) includes 7 - 15 species, with two that have been widely studied as medicinal plants: P. vulgaris (also known as self-heal) and P. lacini$a t a$. Phytochemical studies showed that $P$. vulgaris contains oleanolic, betulinic, ursolic, 2-alpha, 3-alpha-dihydroxyurs-12-en-28-oic and 2-alpha, 3-alpha-ursolic acids, triterpenoids, flavonoids, tannins and anionic polysaccharide prunelline [5,11].

$P$. vulgaris extract can be divided into polar (aqueous) and organic fractions. The polar fraction has been extensively studied with respect to biological (mainly antiviral) activity. Prunelline, the main component of aqueous fraction which is a sulfated polysaccharide exhibits anti-HIV activity [12-16] and prunelline also displays specific activity against the herpes simplex virus type 1 and $2[5,17$, $18]$ as well as HIV infection $[1,11]$. The aqueous fraction of $P$. vulgaris extract inhibits anaphylactic shock and immediate-type allergic reactions as well [19]. It protects rat erythrocytes against haemolysis and kidney and brain homogenates against lipid peroxidation [20]. P. vulgaris aqueous-ethanol extract has also been shown to exhibit scavenger effects on DPPH [21]. Shin found that aqueous extract of $P$. vulgaris inhibits immediate-type allergic reactions in rats [19]. It has been also reported that phenolics-rich extracts from $P$. vulgaris improve antioxidant status in blood and liver and positively affect plasma lipoprotein profile in an experimental model of dietary induced hyperglyceridemia [22].

However, there has been little known about the organic fraction of the $P$. vulgaris extract. The fraction containing significant amounts of rosmarinic acid can be extracted by organic solvents. Triterpenes from $P$. vulgaris have shown anti-inflammatory activity [11]. Rosmarinic acid, a phenolic acid found in P. vulgaris, has been shown to inhibit ultraviolet radiation-induced ability to induce nitrate and superoxide production in monocytes/macrophages [3]. 
Rosmarinic acid is known as the antiviral and antioxidative principle of lemon balm (Melissa officinalis L.) [23-26]. Recently, it was reported that rosmarinic acid might contribute to the antinociceptive property of lemon balm ethanol extract [27].

Rosmarinic acid might be a major bioactive phytochemical found abundantly in $P$. vulgaris. Evidence exists to indicate that rosmarinic acid possesses antiviral and antioxidative activity [26].

Chronic inflammation has been linked to a variety of severe diseases, such as rheumatoid arthritis, inflammatory bowl disease, and various cancers $[28,29]$. Understanding and discovering anti-inflammatory agents may be the key to treating many of these ailments.

Prostaglandin $\mathrm{E}_{2}\left(\mathrm{PGE}_{2}\right)$ is a critical inflammatory mediator that is produced through the arachidonic acid cascade. Two cyclooxygenase isoforms, COX-1 and COX-2 catalyze the reaction converting arachidonic acid, released by phospholipase A, to $\mathrm{PGE}_{2}$. Lipopolysaccharide (LPS) is a common endotoxin used to stimulate macrophage cells to produce $\mathrm{PGE}_{2}$, mimicking an inflammatory response in vitro [30]. The use of RAW264.7 mouse macrophage cells has been a conventional cell model for purposes of identifying extract's and constituent's antiinflammatory activity [31].

The purpose of our study was to examine anti-inflammatory activity in the Prunella extracts prepared with different solvents. It was also important to determine whether rosmarinic acid plays a role in the anti-inflammatory properties.

\section{Materials and Methods}

\subsection{Plant Material and Extraction}

Prunella samples were provided by the USDA-ARS North Central Regional Plant Introduction Station (NCRPIS, Ames, IA, USA). The NCRPI supplied P. vulgaris (Ames 27664) which had been harvested in North Carolina, USA in 2006. After harvest the plant material was prepared for storage by drying for 8 days at $38^{\circ} \mathrm{C}$ in a forcedair dryer with constant humidity. The dried material of Prunella was ground with a 40-mesh screen and stored at $-20^{\circ} \mathrm{C}$ until extraction. Extractions were conducted using appropriate amount of dried Prunella arial part.

Extracts were prepared by Soxhlet method (6 hours). Olvents ranging in hydrophobicity were used for extractions, consisting of ethanol, water, chloroform, or hexane extractions. Upon complete drying of the extract by evaporation, each extract was dissolved in dimethyl sulfoxide (DMSO) (Sigma-Aldrich, St. Louis, MO, USA) at the highest concentration possible. Extracts were stored at $-30^{\circ} \mathrm{C}$ in the dark and used as stock solutions.

\subsection{Endotoxin}

Prunella extracts from NCRPIS were all screened for endotoxin using the Limulus Amebocyte Lysate Test (BioWhittaker, Inc., Walkersville, MD, USA). Measured endotoxin levels from plant extracts ranged from 0 to 0.03 endotoxin units per milliliter $(\mathrm{EU} / \mathrm{mL})$. At these levels the endotoxin found is well below the required amount needed $(>5 \mathrm{EU} / \mathrm{mL})$ to induce the production of $\mathrm{PGE}_{2}$ in RAW264.7 cells due to the fact that the extracts are dissolved in media at the $0.1 \%$ concentration.

\subsection{Cell Culture}

RAW264.7 mouse monocyte/macrophage cells were obtained from American Type Culture Collection (cat: TIB71, Manassas, VA, USA). Cells were cultured in DMEM (Dulbeccos modified eagle's medium) supplemented with $1 \%$ penicillin, $2 \%$ sodium bicarbonate, and $10 \%$ FBS at $37^{\circ} \mathrm{C}, 5 \% \mathrm{CO}_{2}$, and $71 \%$ humidity. Assays were conducted between passages $3-20$. Cells were plated in 24 well plates at a density of $2.0 \times 10^{5}$ cells/well and allowed to grow overnight. Cells were then treated with or without $1 \mu \mathrm{g} / \mathrm{mL}$ LPS for each Prunella extract or fractions at the concentration specified in the results. Treated plates were incubated for 8 hours at $37^{\circ} \mathrm{C}$ and then supernatant was collected and stored at $-80^{\circ} \mathrm{C}$ until analyzed.

\subsection{Measurement of Prostaglandin $E_{2}$}

An enzyme immunoassay (EIA) was used to detect the amount of $\mathrm{PGE}_{2}$ released into the supernatant according to the protocol by Amersham Biosciences, Inc. with slight modification. To remain within detectable $\mathrm{PGE}_{2}$ levels, supernatant samples collected from cell culture were appropriately diluted. Quercetin was purchased for the positive control from Sigma Aldrich, St. Louis, MO, USA.

\subsection{Cytotoxicity}

Celltiter96 Aqueous One Solution Cell Proliferation Assay (Promega Corp., Madison, WI, USA) was used to analyze cytotoxicity following a modified version of Schmitt [32]. RAW264.7 cells were plated into 48 well plates at a density of $0.5 \times 10^{5}$ cells/well and incubated at $37^{\circ} \mathrm{C}$ for $24 \mathrm{hr}$ before treatment. Stock extracts and fractions at $1 \%$ of the total treatment concentration $(0.1 \%$ if shown to be cytotoxic at $1 \%$ ) were randomly assigned to plate wells and incubated for 24 hours using media and DMSO as solvent controls as well as $10 \mu \mathrm{M}, 30 \mu \mathrm{M}$, and $50 \mu \mathrm{M}$ ursolic acid as positive controls. Following the 24-hour incubation period, treatment solutions were removed and fresh media and Celltiter96 dye, was added for 3hours and 15 minutes, which was found to be the optimal incubation time for this study. The metabolized 
dye solutions were then transferred to 96 well plates for absorbance measurement at $562 \mathrm{~nm}$. The number of viable cells for each treatment was compared to the media + DMSO control and the percent of control survival was determined for each extract or fraction.

\subsection{High Performance Liquid Chromatography Analysis and Fractionation}

Fifteen $\mu \mathrm{l}$ of each extract was injected into a Beckman Coulter HPLC with a 508 autosampler, 126-pump control and $168 \mathrm{UV}$-photodiode array detector controlled by 32 karat $^{\mathrm{TM}}$ software (Version 5.0), and a YMC-Pack ODSAM RP C18 $(250 \times 4.6 \mathrm{~mm}, 5 \mu \mathrm{m})$ analytical column (Waters Corp., Milford, MA, USA). Two mobile phases consist of $100 \%$ acetonitrile (mobile phase A) and $0.1 \%$ trifluoric acid (TFA) in water (mobile phase B) with pump rate of $1 \mathrm{~mL} / \mathrm{min}$. The following gradient elution was used (Table 1). For fractionation from 95\% ethanol Prunella extract, prepcolumn and fraction collector were used. The preparation of fractionation was carried out into four parts based on preliminary prep-HPLC chromatogram. Fractions 1, 2, 3, and 4 were collected over the period of retention time between 0 to $20 \mathrm{~min}, 20$ to $66 \mathrm{~min}, 66$ to $100 \mathrm{~min}$, and 100 to $130 \mathrm{~min}$, respectively.

For compound identification, rosmarinic acid and ursolic acid were purchased from Sigma-Aldrich (St. Louis, MO, USA). Compounds were quantified based on the purified standards obtained commercially. The repeatability was determined by analyzing repeated injections of the standard solution.

\subsection{Statistical Analysis}

Prostaglandin $\mathrm{E}_{2}$ levels of treatments were compared to the media + DMSO control by employing a Dunnet multiple comparison test [33]. Data is represented as percent of media + DMSO control set to $100 \%$. Statistical significance was defined as $\mathrm{p}<0.05$ or $\mathrm{p}<0.01$ and $95 \%$ confidence intervals were used. The statistical program used for all analysis was Statistical Analysis Software (SAS) (SAS Institute Inc., Cary, NC, USA).

Table 1. The conditions of prep-HPLC and anal-HPLC.

\begin{tabular}{cccc}
\hline $\begin{array}{c}\text { Time } \\
(\mathrm{min})\end{array}$ & $\begin{array}{c}\text { Mobile phase A } \\
(\% \mathrm{v} / \mathrm{v})\end{array}$ & $\begin{array}{c}\text { Mobile phase B } \\
(\% \mathrm{v} / \mathrm{v})\end{array}$ & Comments \\
\hline $0-30$ & 90 to 70 & 10 to 30 & Linear gradient \\
$30-40$ & 70 to 60 & 30 to 40 & Linear gradient \\
$40-80$ & 60 to 10 & 40 to 90 & Linear gradient \\
$80-90$ & 10 to 0 & 90 to 100 & Linear gradient \\
$90-120$ & 0 & 100 & Isocratic \\
$120-130$ & 0 to 90 & 100 to 10 & $\begin{array}{c}\text { Return to initial } \\
\text { composition } \\
130-140\end{array}$ \\
\hline
\end{tabular}

Cytotoxicity was analyzed using a mixed model, where the plate was considered a random effect. The amount of cytotoxicity for each sample on each plate was analyzed against Media + DMSO control. The amount of cytotoxicity was determined by comparing each extract to the media + DMSO control using a Dunnet-Hsu multiple comparison test [33]. Statistical significance was defined as a $\mathrm{p}<0.05$.

\section{Results and Discussions}

\subsection{HPLC Analyses}

The levels of phytochemical constituents were quantified using HPLC and are listed in Table 2. The Content of rosmarinic acid in Prunella extracts using 95\% ethanol was about $1.4 \mathrm{mM} / 201 \mathrm{mg}$ extract, which has the highest rosmarinic acid content among other extracts prepared with various solvents. We could not observe any rosmarinic acid in $100 \%$ chloroform and hexane extracts.

Lamaison, et al. found rosmarinic acid was the major phenolic component of $P$. vulgaris [21]. Psotova observed $25.7 \% \mathrm{w} / \mathrm{w}$ of rosmarinic acid in methanol extract of $P$. vulgaris (arial parts), which showed antioxidative, antimicrobial, and antiviral effects [10]. The dried and powdered Prunella vulgaris $(2.2 \% \mathrm{w} / \mathrm{w}$ of rosmarinic acid) was extracted with $\mathrm{MeOH}$ at $60^{\circ} \mathrm{C}$ for $24 \mathrm{~h}$.

Toth, et al. reported that rosmarinic acid is an important phenolic active compound of lemon balm (Melissa officinalis L.) [26]. Maximal values in the respective leaf drug samples were found in the plant development phase at harvest. Recently, Miroliaei, et al. observed that lemon balm extract showed anti-glycative action [34].

We also determined rosmarinic acid and ursolic acid in various fractions of $95 \%$ ethanol Prunella extracts. We found $3.9 \mathrm{mM}$ of rosmarinic acid in only fraction 2 collected over the period of retention time between 20 and $66 \mathrm{~min}$ and $4.3 \mathrm{mM}$ ursolic acid in only fractiona 3 collected over the period of retention time between 66 and $100 \mathrm{~min}$ (Table 3).

\subsection{Effect of Prunella Extracts with Various Solvents on $\mathrm{PGE}_{2}$ Production}

To assess anti-inflammatory properties of the Prunella

Table 2. Rosmarinic acid contents in Prunella extracts with various solvents.

\begin{tabular}{ccc}
\hline Label & Extracts & Rosmarinic acid $(\mathrm{mM})$ \\
\hline E1 & Ethanol $100 \%$ & 1.29 \\
E3 & Ethanol $70 \%$ & 1.25 \\
N1 & Ethanol $95 \%$ & 1.36 \\
C1 & Chloroform $100 \%$ & - \\
H1 & Hexane $100 \%$ & - \\
W1 & Water $100 \%$ & 1.16 \\
\hline
\end{tabular}


Table 3. Rosmarinic acid and ursolic acid contents in fractions of 95\% ethanol Prunella extracts.

\begin{tabular}{cccc}
\hline Label & Extracts & Rosmarinic acid $(\mathrm{mM})$ & Rosmarinic acid $(\mathrm{mM})$ \\
\hline F1 & $95 \%$ Ethanol & - & - \\
F2 & $95 \%$ Ethanol & 3.96 & - \\
F3 & $95 \%$ Ethanol & - & 4.34 \\
F4 & $95 \%$ Ethanol & - & - \\
\hline
\end{tabular}

extracts, Soxhlet ethanol, chloroform, hexane, and water extracts were initially screened in RAW264.7 cells at their highest concentration $(0.1 \%$ of the total treatment concentration diluted in media) for their ability to reduce $\mathrm{PGE}_{2}$ levels after stimulation with LPS (Figure 1). The ethanol $70 \%$ and $95 \%$ ethanol extracts of $P$. vulgaris significantly inhibited $\mathrm{PGE}_{2}$ levels at concentrations of 74 and $50 \mu \mathrm{g} / \mathrm{mL}$ each. Prunella extracts from $100 \%$ ethanol, chloroform and hexane did not significantly inhibit $\mathrm{PGE}_{2}$ levels. In our study, Prunella extracts from water showed a tendency of reduction in $\mathrm{PGE}_{2}$ production even though the effect was not significant. Fang, et al. found that polysaccharides isolated from natural sources affect the immune system and have the potential as immunomodulators with wide clinical applications [3].

Sun, et al. reported that the ethanol extract of Spica Prunellae ( $P$. vulgaris fruiting spikes) consisting of a mixture of triterpenoids, flavonoids, tannins and polysaccharide could suppress the cellular and humoral response in mice [35].

\subsection{Effect of Fractions from $95 \%$ Ethanol Prunella Extracts on $\mathrm{PGE}_{2}$ Production}

We focused on $95 \%$ ethanol Prunella extracts and fractionated into 4 parts based on chromatogram of prep-HPLC. Fraction 2 whose major component is rosmarinic acid showed a significant rduction in $\mathrm{PGE}_{2}$ production compared to other fractions. There was no inhibition of $\mathrm{PGE}_{2}$ production due to the presence of ursolic acid which are the major component in fraction 3 from 95\% ethanol Prunella extract (Figure 2). Our observation was contrast with the result of Ryu, et al. who found strong inhibitory effects of anti-allergic and anti-inflammatory triterpenes (especially ursolic acid and 2-alpha-hydroxyursolic acid) from $P$. vulgaris methanol extract [11].

\subsection{Dose-Response of Fraction II from $95 \%$ Ethanol Prunella Extract on $\mathrm{PGE}_{2}$ Production}

We examined whether fractions from $95 \%$ ethanol Prunella extracts affect $\mathrm{PGE}_{2}$ production in a dose-response manner. As shown in Figure 3, there was a dose-dependent reduction in $\mathrm{PGE}_{2}$ production of fraction 2 containing mainly rosmarinic acid.

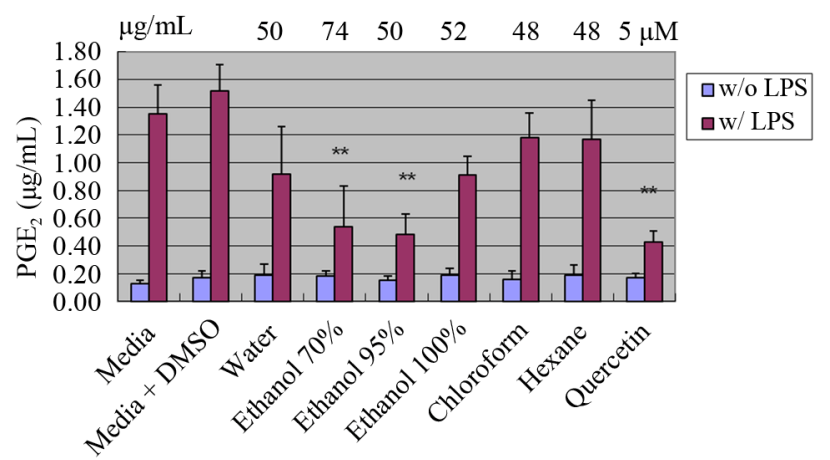

Figure 1. Effect of Prunella extracts with various solvents on $\mathrm{PGE}_{2}$ production in RAW 264.7 cells. Values are means \pm $\mathrm{SEM}, \mathrm{n}=5$. ${ }^{* *}$ Significantly different than the control, $\mathrm{p}<0.01$.

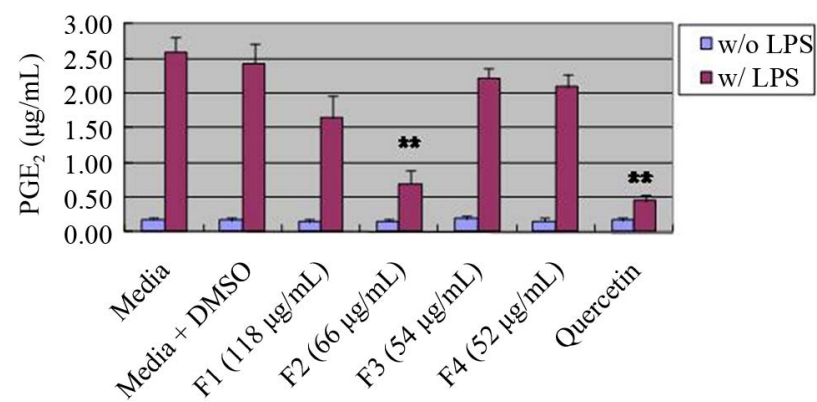

Figure 2. Effect of fractions from ethanol 95\% Prunella

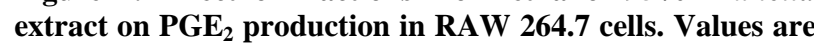
means \pm SEM, $n=5$. ${ }^{* *}$ Significantly different than the control, $\mathrm{p}<\mathbf{0 . 0 1}$.

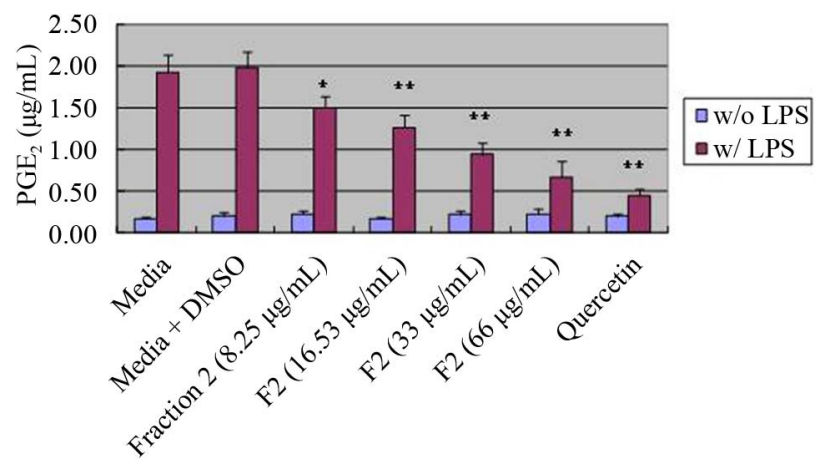

Figure 3. Dose-response of fraction II from $95 \%$ ethanol Prunella extract on $\mathrm{PGE}_{2}$ production in RAW 264.7 cells. Values are means \pm SEM, $n=5$. * Significantly different than the control, $p<0.05$. ${ }^{* *}$ Significantly different than the control, $\mathrm{p}<0.01$.

Recently, it was reported that $P$. vulgaris extracts $(5,10$, $25 \mu \mathrm{g} / \mathrm{mL})$ and its component rosmarinic acid $(1 \mu \mathrm{g} / \mathrm{mL})$ showed LPS-induced oxidative damage and inflammation in human gingiviral fibroblasts [36].

\subsection{Screening for Cytotoxicity in Extracts and Fractions of $P$. vulgaris}

To determine whether any of extracts and fractions had 
the ability to arrest metabolic activity in RAW264.7 macrophage cells and to provide further evidence that the observed $\mathrm{PGE}_{2}$ reduction with treatment of Prunella extracts was not due to cytotoxicity, a parallel study using the Celltiter96 Aqueous One Solution Cell Proliferation Assay was conducted. Ursolic acid, a triterpenoid known for its cytotoxic activities [37], was used as a positive control at concentrations of $10 \mu \mathrm{M}, 30 \mu \mathrm{M}$, and $50 \mu \mathrm{M}$. The extracts prepared using chloroform showed significant cytotoxicity $(p>0.05)$ at the $1 \%$ concentration and 24 hours incubation. There was no cytotoxicity in other extracts and fractions prepared with ethanol, water and hexane except chloroform.

In summary, this study indicates that Prunella extracts may be able to modulate inflammation though their inhibitory activity on $\mathrm{PGE}_{2}$ production and that rosmarinic acid is possible key constituent in the observed anti-inflammatory properties.

\section{Acknowledgements}

We thank Dr. D. Birt and Dr. P. Murphy of the Center for Research Botanical Dietary Supplements at Iowa State University for their useful help.

\section{REFERENCES}

[1] D. Chattopadhyay, M. Chawla-Sarkar, T. Chatterjee, R. S. Dey, P. Bag, S. Chakraborti and M. T. Khan, "Recent Advancements for the Evaluation of Anti-Viral Activities of Natural Products," New Biotechnology, Vol. 25, No. 5, 2009, pp. 347-368. doi:10.1016/j.nbt.2009.03.007

[2] X. Fang, R. C. Chang, W. H. Yues and S. Y. Zee, "Immune Modulatory Effects of Prunella vulgaris L.," International Journal of Molecular Medicine, Vol. 15, No. 3, 2005, pp. 491-496.

[3] X. Fang, M. M. Yu, W. Yuen, S. Y. Zee and R. C. Chang, "Immune Modulatory Effects of Prunella vulgaris L. on Monocytes/Macrophages," International Journal of Molecular Medicine, Vol. 16, No. 6, 2005, pp. 1109-1116.

[4] T. K. Au, T. L. Lam, T. B. Ng, W. P. Fong and D. C. Wan, "A Comparison of HIV-1 Integrase Inhibition by Aqueous and Methanol Extracts of Chinese Medicinal Herbs," Life Sciences, Vol. 68, No. 14, 2001, pp. 16871694. doi:10.1016/S0024-3205(01)00945-6

[5] H. X. Xu, S. H. Lee, S. F. Lee, R. L. White and J. Blay, "Isolation and Characterization of an Anti-HSV Polysaccharide from Prunella vulgaris," Antiviral Research, Vol. 44, No. 1, 1999, pp. 43-54. doi:10.1016/S0166-3542(99)00053-4

[6] G. Zhang, L. He and M. Hu, "Optimized Ultrasonic-Assisted Extraction of Flavonoids from Prunella vulgaris L. and Evaluation of Antioxidant Activities in Vitro," Innovative Food Science and Emerging Technologies, Vol. 12, No. 1, 2011, pp. 18-25. doi:10.1016/j.ifset.2010.12.003

[7] J. Psotova, A. Svobodova, H. Kolarova and D. Walterova, "Photoprotective Properties of Prunella vulgaris and
Rosmarinic Acid on Human Keratinocytes," Journal of Photochemistry and Photobiology B: Biology, Vol. 84, No. 3, 2006, pp. 167-174. doi:10.1016/i.jphotobiol.2006.02.012

[8] S. Ramachandran and N. R. Prasad, "Effect of Ursolic Acid, a Triterpenoid Antioxidant, on Ultraviolet-B Radiation-Induced Cytotoxicity, Lipid Peroxidation and DNA Damage in Human Lymphocytes," Chemico-Biological Interations, Vol. 176, No. 2-3, 2009, pp. 99-107. doi:10.1016/j.cbi.2008.08.010

[9] U. S. Harput, I. Saracoglu and Y. Ogihara, "Effects of Two Prunella Species on Lymphocyte Proliferation and Nitric Oxide Production," Phytotherapy Research, Vol. 20, No. 2, 2006, pp. 157-159. doi:10.1002/ptr.1805

[10] J. Psotova, M. Kolar, J. Sousek, Z. Svagera, J. Vicar and J. Ulrichova, "Biological Activities of Prunella vulgaris Extract," Phytotherapy Research, Vol. 17, No. 9, 2003, pp. 1082-1087. doi:10.1002/ptr.1324

[11] S. Y. Ryu, M. H. Oak, S. K. Yoon, D. I. Cho, G. S. Yoo, T. S. Kim and K. M. Kim, "Anti-Allergic and Anti-Inflammatory Triterpenes from the Herb of Prunella vulgaris," Planta Medica, Vol. 66, No. 4, 2000, pp. 358-360. doi:10.1055/s-2000-8531

[12] S. Liu, S Jiang, Z. Wu, L. Lv, J. Zhang, Z. Zhu and S. Wu, "Identification of Inhibitors of the HIV-1 gp41 Six-Helix Bundle Formation from Extracts of Chinese Medicinal Herbs Prunella vulgaris and Rhizoma cibotte," Life Sciences, Vol. 71, No. 15, 2002, pp. 1779-1791. doi:10.1016/S0024-3205(02)01939-2

[13] S. Kageyama, M. Kurokawa and K. Shirake, "Extract of Prunella vulgaris Spikes Inhibits HIV Replication at Reverse Transcription in Vitro and Can Be Absorbed from Intestine in Vivo," Antivirus Chemistry and Chemotherapy, Vol. 11, No. 2, 2000, pp. 157-164.

[14] T. L. Lam, M. L. Lam, T. K. Au, D. T. IP, T. B. Ng, W. P. Fong and D. C. Wan, "A Comparison of Human Immunodeficiency Virus Type-1 Protease Inhibition Activities by the Aqueous and Methanol Extracts of Chinese Medicinal Herbs," Life Sciences, Vol. 67, No. 23, 2000, pp. 2889-2896. doi:10.1016/S0024-3205(00)00864-X

[15] K. Yamasaki, M. Nakano, T. Kawahata, H. Mori, T. Otake, N. Ueba, I. Oishi, R. Inami, M. Yamane, M. Nakamura, H. Murata and T. Nakanish, "Anti-HIV-1 Activity of Herbs in Labiatae," Biological and Pharmaceutical Bull, Vol. 21, No. 8, 1998, pp. 829-833. doi:10.1248/bpb.21.829

[16] H. D. Tabba, R. S. Chang and K. M. Smith, "Isolation, Purification, and Partial Characterization of Prunellin, an Anti-HIV Component from Aqueous Extracts of Prunella vulgaris," Antiviral Research, Vol. 11, No. 5-6, 1989, pp. 263-273. doi:10.1016/0166-3542(89)90036-3

[17] L. C. Chiu, W. Zhu and V. E. Ooi, "A Polysaccharide Fraction from Medicinal Herb Prunella vulgaris Downregulates the Expression of Herpes Simplex Virus Antigen in Vero Cells," Journal of Ethnopharmacology, Vol. 93, No. 1, 2004, pp. 63-68. doi:10.1016/j.jep.2004.03.024

[18] X. J. Yao, M. A. Wainberg and M. A. Parniak, "Mechanism of Inhibition of HIV-1 Infection in Vitro by Purified Extract of Prunella vulgaris," Viology, Vol. 187, No. 1, 
1992, pp. 56-62. doi:10.1016/0042-6822(92)90294-Y

[19] T. Y. Shin, Y. K. Kim and H. M. Kim, "Inhibition of Immediate-Type Allergic Reactions by Prunella vulgaris in a Murine Model," Immunopharmocology and Immunotoxicology, Vol. 23, No. 3, 2001, pp. 423-435. doi:10.1081/IPH-100107341

[20] F. Liu and T. B. Ng, "Anti-Oxidative and Free Radical Scavenging Activities of Selected Medicinal Herbs," Life Sciences, Vol. 66, No. 8, 2000, pp. 725-735. doi:10.1016/S0024-3205(99)00643-8

[21] J. L. Lamaison, C. Petitjean-Freytet and A. Carnat, "Medicinal Laminaceae with Antioxidant Properties, a Potential Source of Rosmarinic Acid," Pharmaceutica Acta Helvetiae, Vol. 66, No. 7, 1991, pp. 185-188.

[22] N. Skottavá, L. Kazdová, O. Oliyarnyk, R. Vecera, L. Sobolová and J. Ulrichová, "Phenolics-Rich Extracts from Silybum Marianum and Prunella vulgaris Reduce a High-Sucrose Diet Induced Oxidative Stress in Hereditary Hypertriglyceridemic Rats," Pharmacological Research, Vol. 50, No. 2, 2004, pp. 123-130. doi:10.1016/j.phrs.2003.12.013

[23] C. Weitzel and M. Petersen, "Cloning and Characterization of Rosmarinic Acid Synthase from Melissa officinalis L.," Phytochemistry, Vol. 72, No. 7, 2011, pp. 572578. doi:10.1016/j.phytochem.2011.01.039

[24] S. Kim, E. J. Yun, J. S. Bak, H. Lee, S. J. Lee, C. T. Kim, J. H. Lee and K. H. Kim, "Response Surface Optimized Extraction and Chromatographic Purification of Rosmarinic Acid from Melissa officinalis Leaves," Food Chemistry, Vol. 121, No. 2, 2010, pp. 521-526. doi:10.1016/j.foodchem.2009.12.040

[25] M. Öztürk, M. E. Duru, B. İnce, M. Harmandar and G. Topçu, "A New Rapid Spectrophotometric Method to Determine the Rosmarinic Acid Level in Plant Extracts," Food Chemistry, Vol. 123, No. 4, 2010, pp. 1352-1356. doi:10.1016/j.foodchem.2010.06.021

[26] J. Toth, M. Mrlianová, D. Tekel'Ová and M. Korenová, "Rosmarinic Acid. An Important Phenolic Active Compound of Lemon Balm (Melissa officinalis L.)," Acta Facultatis Pharmanceutical Universitatis Comenianae, Vol. 50, 2003, pp. 139-146.

[27] G. Guginski, A. P. Luiz, M. D. Silva, M. Massaro, D. F. Martins, J. Chaves, R. W. Mattos, D. Silveira, V. M. M. Ferreira, J. B. Calixto and A. R. S Santos, "Mechanisms Involved in the Antinociception Caused by Ethanolic Extract Obtained from the Leaves of Melissa officinalis (Lemon Balm) in Mice," Pharmacology, Biochemistry and Behavior, Vol. 93, No. 1, 2009, pp. 10-16. doi:10.1016/j.pbb.2009.03.014
[28] J. Rhodes and P. Collins, "Lessons for Inflammatory Bowel Disease from Rheumatology," Digestive and Liver Disease, Vol. 38, No. 3, 2006, pp. 157-162. doi:10.1016/j.dld.2005.09.020

[29] H. Lu, W. Ouyang and C. Huang, "Inflammation, a Key Event in Cancer Development," Molecular Cancer Research, Vol. 4, No. 4, 2006, pp. 221-233. doi:10.1158/1541-7786.MCR-05-0261

[30] R. Patel, M. G. Attur, M. Dave, S. B. Abramson and A. R. Amin, "Regulation of Cytosoic COX-2 and Prostaglandin $\mathrm{E}_{2}$ Production by Nitric Oxide in Activated Murine Macrophages," Journal of Immunology, Vol. 162, No. 7, 1999, pp. 4191-4197.

[31] Y. Chen, T. Fu, T. Tao, J. Yang, Y. Chang, M. Wang, L. Kim, L. Qu, J. Cassady, R. Scalzo and X. Wang, "Macrophage Activating Effects New Alkamides from the Roots of Echinacea Species," Journal of Natural Products, Vol. 68, No. 5, 2005, pp. 773-776. doi:10.1021/np040245f

[32] L. Schmitt, Y. Liu, P. Murphy and D. Birt, "Evaluation of the Light-Sensitive Cytotoxicity of Hypericum perforatum Extracts, Fractions, and Pure Compounds," Journal of Agricultural and Food Chemistry, Vol. 54, No. 8, 2006, pp. 2881-2890. doi:10.1021/jf052344k

[33] C. W. Dunnett, "A Multiple Comparison Procedure for Comparing Several Treatments with a Control," Journal of the American Statistical Association, Vol. 50, No. 272, 1955, pp. 1096-1121. doi:10.1080/01621459.1955.10501294

[34] M. Miroliaei, S. Khazaei, S. Moshkelgosha and M. Shirvani, "Inhibitory Effects of Lemon Balm (Melissa officinalis L.) Extract on the Formation of Advanced Glycation End Products," Food Chemistry, Vol. 129, No. 2, 2011, pp. 267-271. doi:10.1016/j.foodchem.2011.04.039

[35] H. Sun, F. Qin and Y. Pan, "In Vitro and in Vivo Immunosuppressive Activity of Spica Prunellae Ethanol Extract on the Immune Responses in Mice," Journal of Ethnopharmacology, Vol. 101, No. 1-3, 2005, pp. 31-36. doi:10.1016/i.jep.2005.03.023

[36] A. Zdařilová, A. Svobodová, V. Šimánek and J. U1richová, "Prunella vulgaris Extract and Rosmarinic Acid Suppress Lipopolysaccharide-Induced Alteration in $\mathrm{Hu}-$ man Gingival Fibroblasts," Toxicology in Vitro, Vol. 23, No. 3, 2009, pp. 386-392. doi:10.1016/j.tiv.2008.12.021

[37] F. Resende, C. Barcala, M. Faria, F. Kato, W. Cunha and D. Tavares, "Antimutagenicity of Ursolic Acid and Oleanolic Acid against Doxorubicin-Induced Clastogenesis in Balb/c Mice," Life Sciences, Vol. 79, No. 13, 2006, pp. 1268-1273. doi:10.1016/j.lfs.2006.03.038 